\title{
Correction to: "The etherealization of common sense?" Arithmetical and algebraic modes of intelligibility in late Victorian mathematics of measurement
}

\section{Daniel Jon Mitchell ${ }^{1}$}

Published online: 21 December 2018

(c) Springer-Verlag GmbH Germany, part of Springer Nature 2018

\section{Correction to: Archive for History of Exact Sciences https://doi.org/10.1007/s00407-018-0218-y}

The original HTML version of this article unfortunately contained mistakes. The position of Figs. 1, 2 and 3 was incorrect. In the new version of the article, the position of the figures has been corrected.

The original HTML version of this article was corrected.

The Publisher apologizes for any inconvenience caused.

The original article can be found online at https://doi.org/10.1007/s00407-018-0218-y.

$凶 \quad$ Daniel Jon Mitchell

mitchell@physik.rwth-aachen.de

1 Institute for Theoretical Physics and Cosmology, RWTH Aachen, Sommerfeldstr. 16, 52074 Aachen, Germany 